ISSN 1112-9867

Available online at

http://www.jfas.info

\title{
NUMERICAL SIMULATION AND MODELING OF UNSTEADY FLOW AROUND AN AIRFOIL. (AERODYNAMIC FORM)
}

\author{
M. Y. Habib ${ }^{1}$, R. Djaaffar*2
}

${ }^{1}$ Laboratoire LTE, Département de Génie mécanique, ENSET Oran, Algérie.

${ }^{2}$ Laboratoire de Physique des Plasmas, Matériaux Conducteurs et leurs Applications.

Département de physique. Université des Sciences et de la Technologie d'Oran, Algérie.

Received: 22 March 2014 / Accepted: 22 June 2014 / Published online: 30 June 2014

\begin{abstract}
During this work, we simulated an unsteady flow around an airfoil type NACA0012 using the Fluent software. The objective is to control the code on the one hand and on the other hand the simulation of unsteady flows. By simulating an unsteady flow Reynolds number $(\operatorname{Re}=$ $6.85 * 106)$ and Mach number $(\mathrm{M}=0.3)$, we have the flowing with a grid (mesh) adequate numerical results and experimental data are in good agreement. To represent the results of the simulation we have validated by comparing the values of aerodynamic coefficients with those of experimental data.
\end{abstract}

Keywords: Unsteady flow; Fluent; a single equation model; NACA0012.

\section{INTRODUCTION}

Predetermination of unsteady flow was always a concern for the research because the implementation difficult in laboratories and sophisticated equipment requirements. Our objective of this study is to control the simulation of unsteady flows around structures.

Author Correspondence, e-mail: djaaffar31@yahoo.fr

ICID: 1111610 
Using the finite volume method and Spalart-Allmars model, designed for applications in Aerospace, our results were in good agreement with experimental data. By simulation studies predeterminations became very easy to prepare, this gain is the result of the development of computational methods and hardware remarkable revolution. So mastery of computers has become indispensable for such studies simulation. Representations available in the Fluent software allowed me to understand the discipline of an unsteady flow. For this work we simulated unsteady flow around a NACA0012 profile type in the following conditions:

Iso-thermal wall at $300^{\circ} \mathrm{k}$; Fluid temperature $300^{\circ} \mathrm{K}$; Atmospheric pressure, $\mathrm{P}=101325 \mathrm{~Pa}$; Reynolds number, $\operatorname{Re}=6.84$.106; Mach number, $\mathrm{M}=0.3$; Angle of incidence, $\alpha=4$; Relationship for the viscosity of Sutherland.

\section{TURBULENCE MODELING:}

Modeling is by definition an approximation of reality, so its results are always more or less close to the experimental data. It was resolved the Navier-Stokes Reynolds averaged using a single closed equation, which models the Reynolds stress $\left(-\rho\left(u_{-} i U_{-} j\right)\right)$ by solving the transport equation for the turbulent kinematic viscosity this model proposed by SpalartAllmaras.

The equations of continuity and Navier-Stokes Reynolds averaged are given by:

$$
\begin{gathered}
\frac{\partial \rho}{\partial t}+\frac{\partial}{\partial x_{i}}\left(\rho U_{i}\right)=0 \\
\frac{\partial}{\partial t}\left(\rho U_{i}\right)+\frac{\partial}{\partial x_{i}}\left(U_{I} U_{i}\right)=\frac{\partial p}{\partial x_{i}}+\frac{\partial}{\partial x_{j}}\left[\mu\left(\frac{\partial U_{i}}{\partial x_{j}}+\frac{\partial U_{j}}{\partial x_{i}}-\frac{2}{3} \delta_{i j} \frac{\partial U_{i}}{\partial x_{j}}\right)\right]+\frac{\partial}{\partial x_{j}}(-\rho \text { injiji } \bar{i})
\end{gathered}
$$

The equation connectingete Reynolds stress with the average speed is the following:

$$
-\rho \bar{i} \mid i_{i} \cdot i_{j}^{\bar{T}}=\mu_{t}\left(\frac{\partial U_{i}}{\partial x_{j}}+\frac{\partial U_{j}}{\partial x_{i}}\right) \frac{2}{3}\left(\rho k+\pi_{t} \frac{\partial U_{k}}{\partial x_{k}}\right) \delta_{i j}
$$

$\mu_{t}$ : turbulent viscosity;

$k$ : Kinetic energy of turbulence.

The transport equation for turbulent kinematic viscosity $(v)$ is:

$$
\frac{\partial}{\partial t}(\rho \tilde{v})+\frac{\partial}{\partial x_{i}}\left(\rho \tilde{v} u_{i}\right)=G_{v}+\frac{1}{\sigma_{\widetilde{v}}}\left[\frac{\partial}{\partial x_{j}}\left\{(\mu+\rho \tilde{v}) \frac{\partial \widetilde{v}}{\partial x_{j}}\right\}+C_{b 2} \rho\left(\frac{\partial \widetilde{v}}{\partial x_{j}}\right)^{2}\right]-Y_{v}+S_{\widetilde{v}}
$$

$G_{v}:$ The production of turbulent viscosity;

$Y_{v}$ : The destruction of turbulent viscosity;

$\sigma_{\widetilde{v}}$ and $C_{b 2}:$ Constants;

$S_{\widetilde{v}}$ : the user"s defined source. 
The kinetic energy of turbulence, $\mathrm{k}$ will not be calculated.

\section{GEOMETRY AND MESH:}

See the figures 1,2 and 3 .

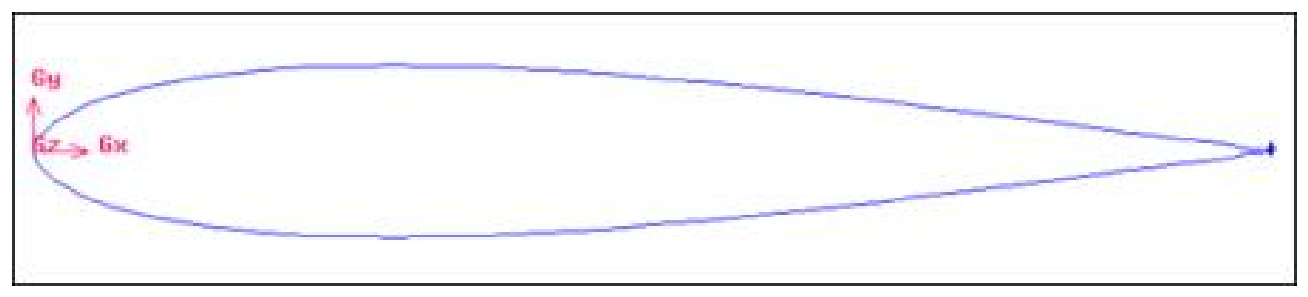

Fig.1. Naca0012 profile.

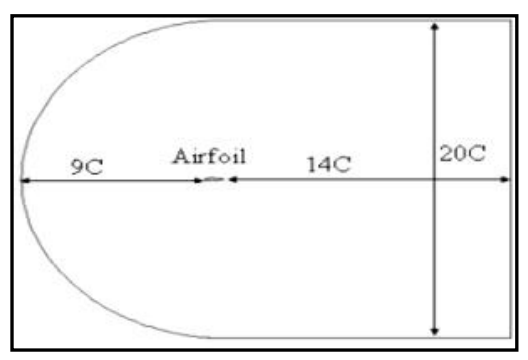

Fig.2. Domain of camputation

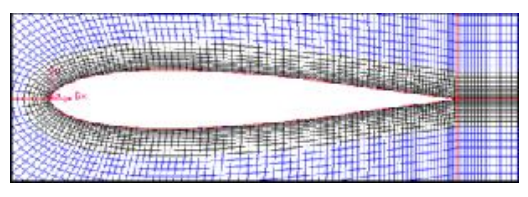

Fig.3. Mesh near the profile

\section{STUDY OF DEPENDENCE IN MESH:}

In order to check the mesh dependency or not the simulation of steady flow at $10^{\circ}$ incidence is made by calculating four cases by conducting a mesh adaptation to the walls for the 3rd and 4th cases, the results are affirmative for dependence and the thickness of the first mesh affects the simulation results.

The values of lift coefficient were improved after modifications of the mesh, however the accuracy of convergence is higher for the first adaptation and stepped back for seconds. It is advisable to choose a good convergence criterion not to waste time calculating assets without a converged solution. Figures 4 to 8 . 


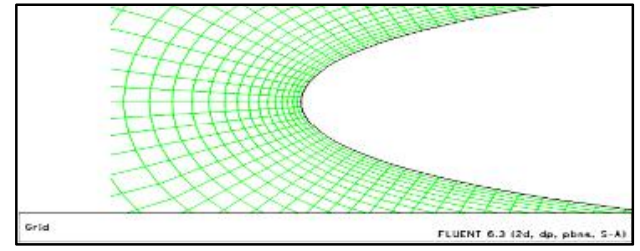

Fig. 4. Mesh whitout adaptation

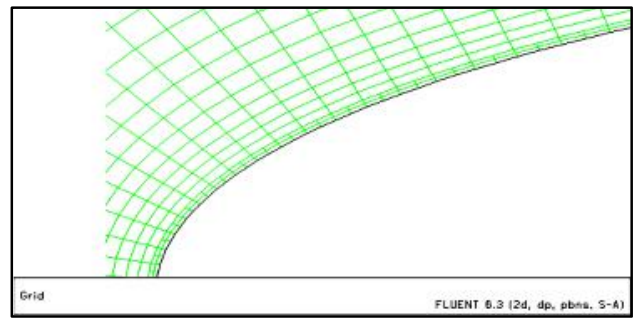

Fig.5. Mesh after first adaptation

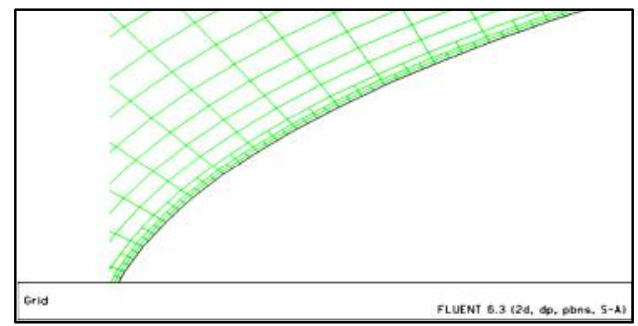

Fig.6. Mesh after second adaptation

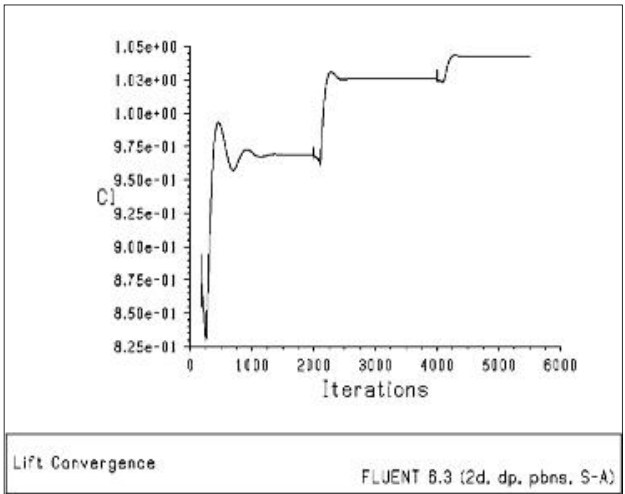

Fig.7. hystorical convergence of lift 


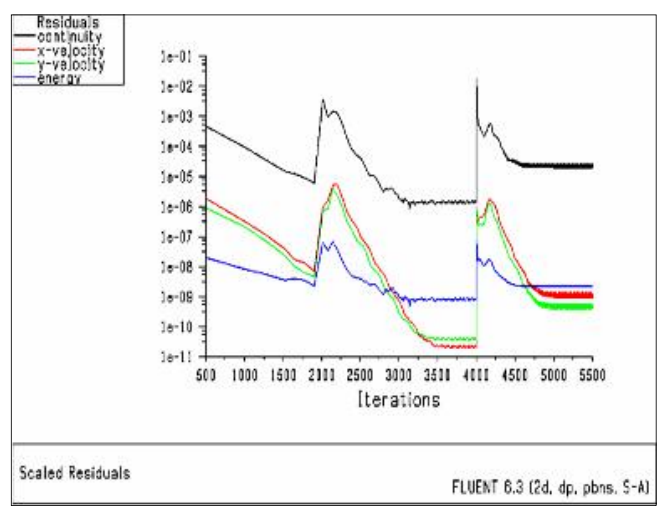

Fig.8. hystorical scales residuals

\section{VALIDATION OF RESULTS:}

To validate our results, we compared the values of the coefficients of drag and lift with the experimental data obtained by N. And Gregory N. P. Welby. These values are taken for both cases for each incidence angle. V1 is taken after the convergence of the continuity equation for a test $10^{3}$ and $\mathrm{V} 2$ after the zero convergence of these coefficients. (Figures 9 and 10).

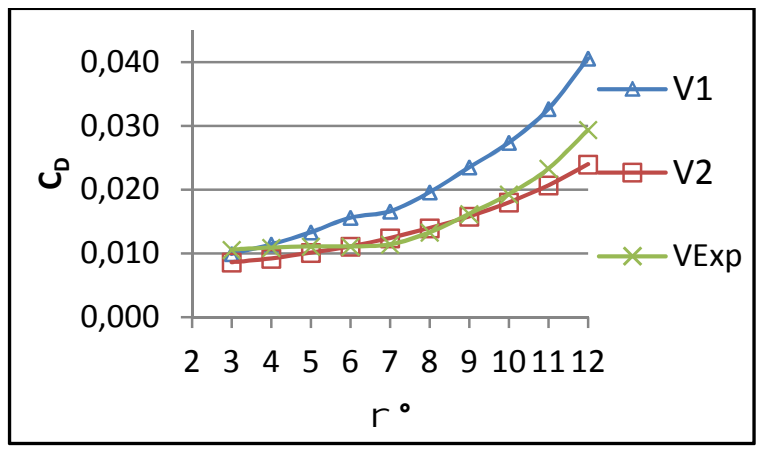

Fig.9. drag coefficient a function of angle of attack, $M=0.4$

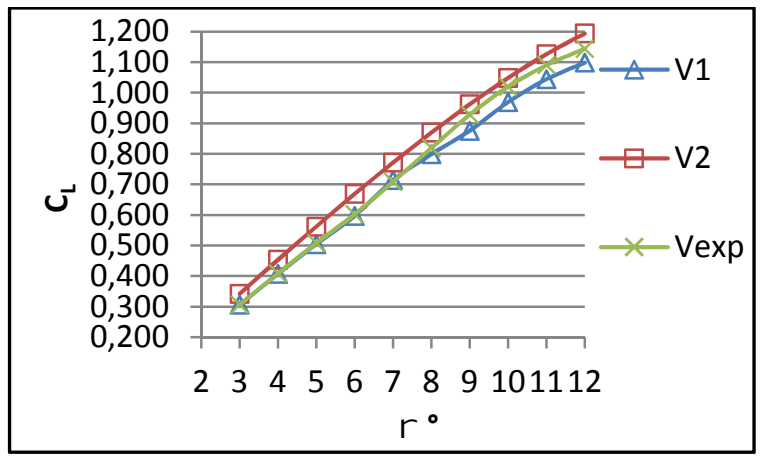

Fig.10. drag coefficient a function of angle of attack, $M=0.4$ 


\section{REPRESENTATIONS OF STEADY RESULTS:}

We represented the stationary results in order to use them to initiate the unsteady calculation and avoid oscillations composition in the transient portion of the flow. Figures 11 to 14.

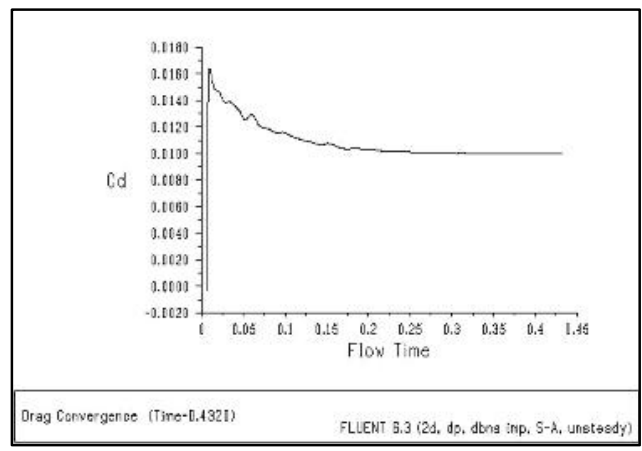

Fig.11. Drag convergence for steady flow

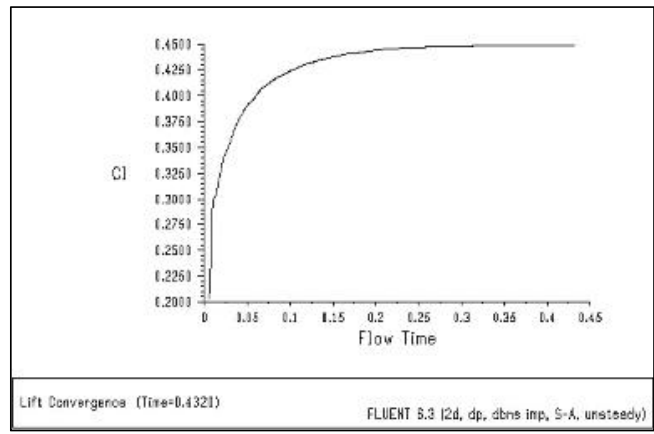

Fig.12. Lift convergence for steady flow

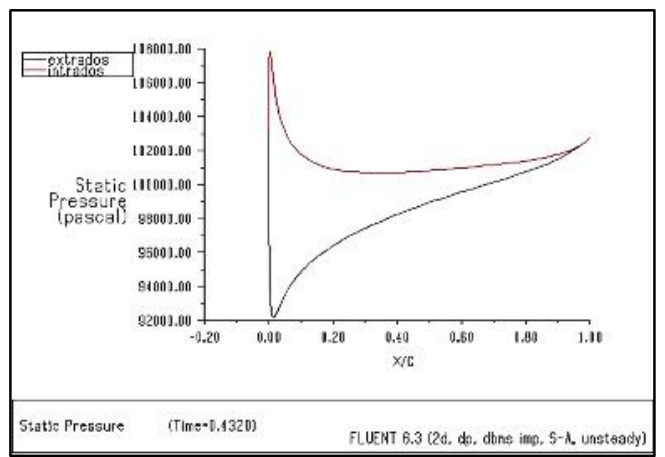

Fig.13. Distribution of Static pressure around the airfoil 


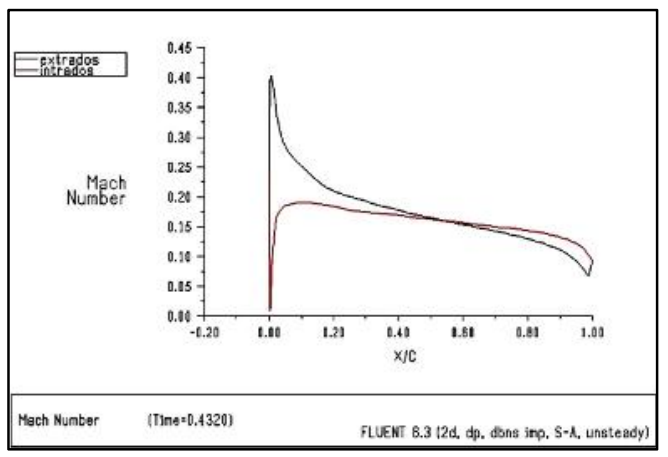

Fig.14. Distribution of Mach number around the airfoil

\section{REPRESENTATIONS OF UNSTEADY RESULTS:}

To simulate the unsteady flow we used a static pressure pulse to the input of area to get the Mach 0.32> M>0.278. This pulse is defined by the general equation $[\mathrm{P}=\mathrm{A} \sin (\omega . \mathrm{t})+\mathrm{Patm}]$. The figures above (15 to 18) highlight the difference between steady results and those unsteady.

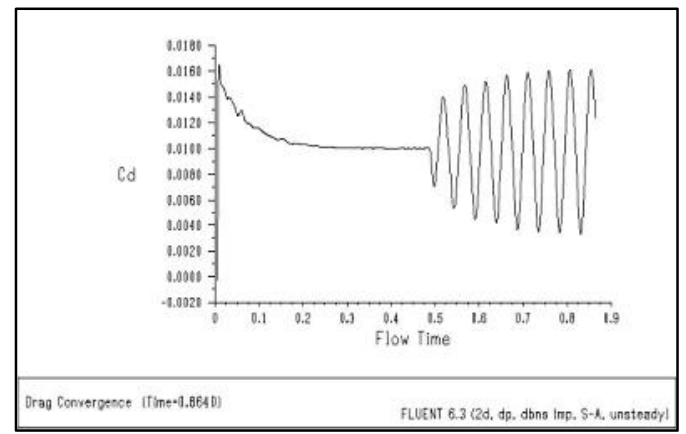

Fig.15. Drag convergence for unsteady flow

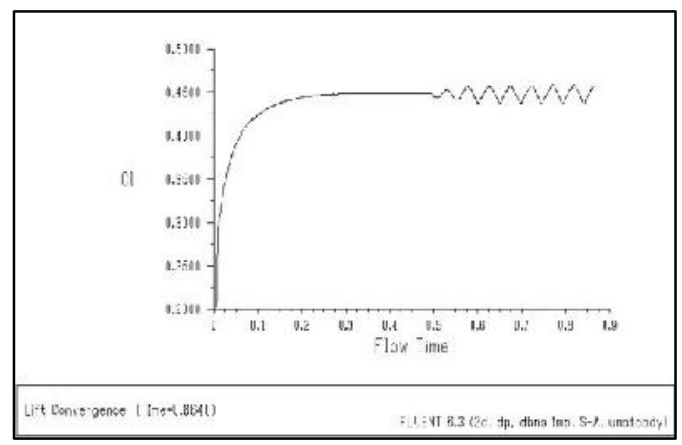

Fig.16. Lift convergence for unsteady flow 


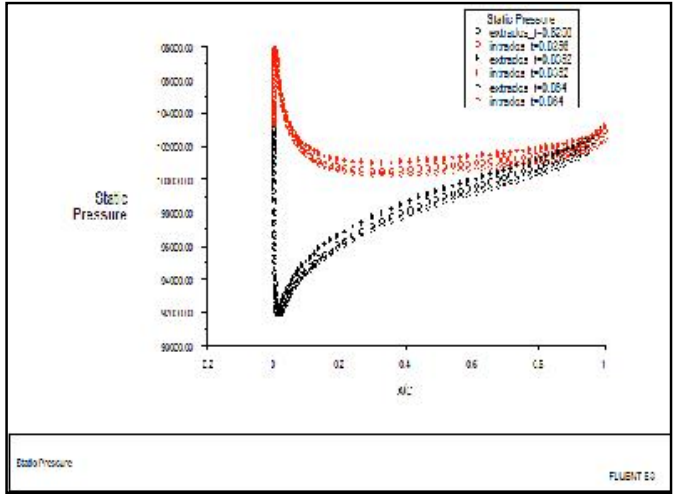

Fig.17. Distributions of instantaneous static pressure around the airfoil

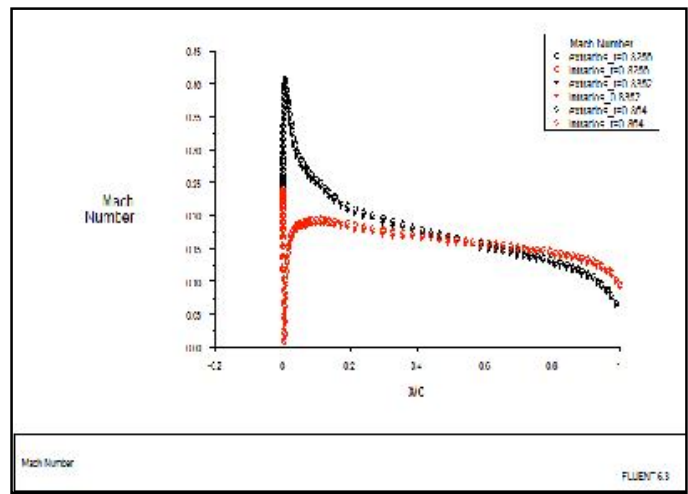

Fig. 18. Distributions of instantaneous static pressure around the airfoil

\section{LES ISO-CONTOURS INSTANTANES DE LA PRESSION STATIQUE:}

The different Iso-contours are represented to highlighting the diffences between the contours of the instantaneous static pressure. Figures 19 to 24.

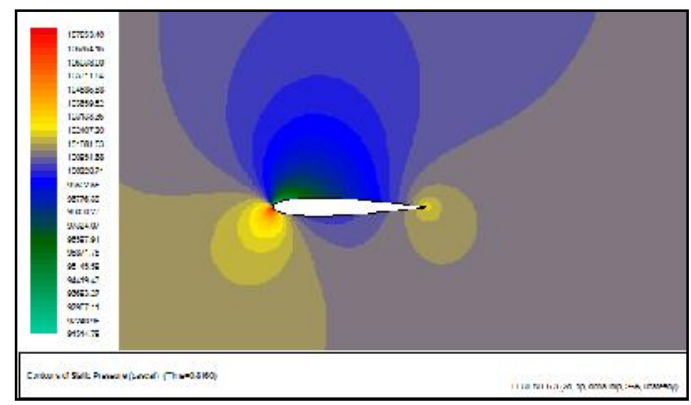

Fig.19. Iso-contour of static pressure at $\mathrm{t}=0.816 \mathrm{~s}$. 


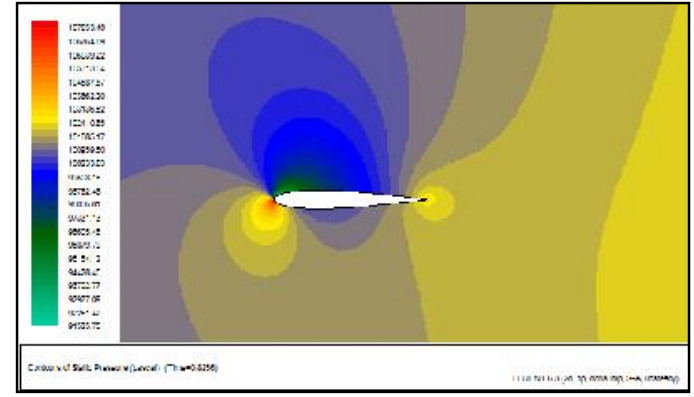

Fig.20. Iso-contour of static pressure at $t=0.8256 \mathrm{~s}$.

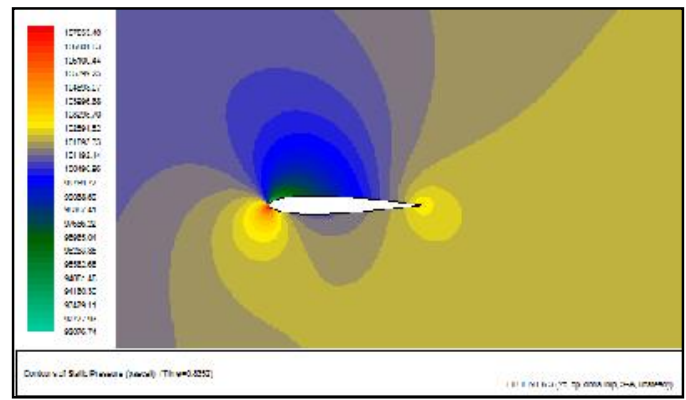

Fig.21. Iso-contour of static pressure at $\mathrm{t}=0.8352 \mathrm{~s}$.

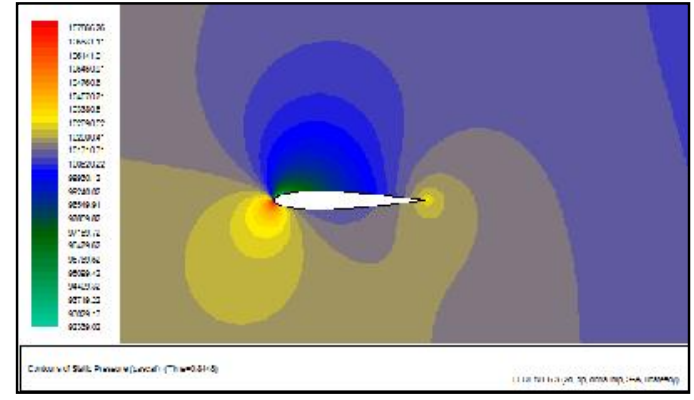

Fig.22. Iso-contour of static pressure at $t=0.8448 \mathrm{~s}$.

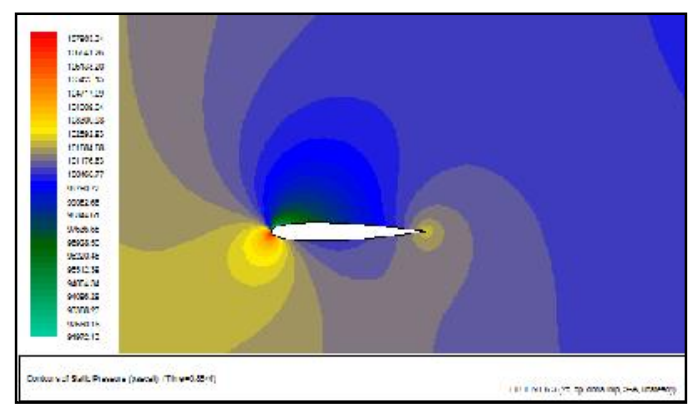

Fig.23. Iso-contour of static pressure at $\mathrm{t}=0.8544 \mathrm{~s}$. 


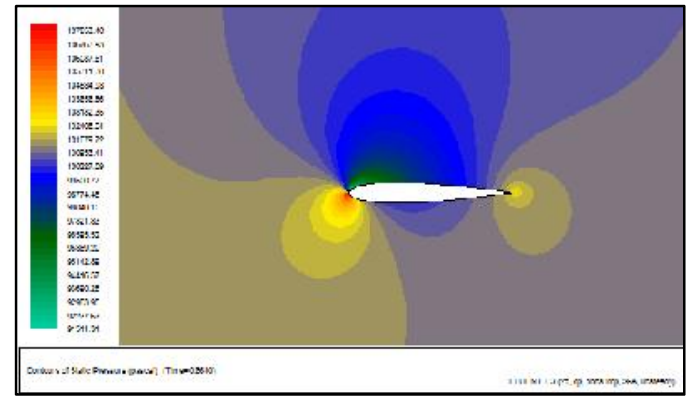

Fig.24. Iso-contour of static pressure at $\mathrm{t}=0.864 \mathrm{~s}$.

\section{CONCLUSION}

The historical convergences of the aerodynamic coefficients highlight the influence of changing the speed at infinite upstream of these coefficients. The oscillation of coefficients produces a vibration of aircraft wings will, in view of the rigidity of the wing is the cause vibration by the flowing fluid.

The Iso-contours of the instantaneous static pressure represented illustrate the dependence of the flow time, so the flow is unsteady and the pressure distribution around the profile changes from one moment to another by oscillating the aerodynamic coefficients. Thus the oscillation of static pressure is defined boundary conditions at the origin of the variation of the speed and therefore Mach number. To conclude our study, with an adequate grid and well-chosen approach the numerical results and ones experimental are in good concordance. so boundary conditions must be well defined.

\section{REFERENCES}

[01] P. Spalart and S. Allmaras, 1992. A one-equation turbulence model for aerodynamic flows. Technical Report AIAA-92-0439, American Institute of Aeronautics and Astronautics. [02] L. Chatellier, 2005. Course: unsteady fluid mechanics.

[03] C. Robert Nelson 1998. Flight Stability and Automatic Control, second edition. International Editions.

[04] Documentation provided with Fluent software, Fluent 6.3 User's Guide 2006.

[05] D. Choudhury, 1993. Introduction to the Renormalization Group Method and Turbulence Modeling. Fluent Inc. Technical Memorandum TM-107.

[06] D. Bourguet, 2008. Physical analysis and modeling of unsteady compressible turbulent flows around airfoils by statistical approaches high fidelity and small size in the context of 
fluid-structure interaction. Issued by the Institut National Polytechnique de Toulouse Specialty: Fluid Dynamics.

[07] J. O. Hinze, 1975. Turbulence. $1^{\text {st }}$ edition. McGraw-Hill Publishing Co., New York.

[08] B. E. Launder and D. B. Spalding, 1972. Lectures in Mathematical Models of Turbulence. $2^{\text {nd }}$ edition. Academic Press, London.

[09] T.-H. Shih, W. W. Liou, A. Shabbir, Z. Yang, and J. Zhu, 1995. A New k-€ EddyViscosity Model for High Reynolds Number Turbulent Flows - Model Development and Validation. Computers Fluids, 24(3):227-238.

[10] D. C. Wilcox, 1998. Turbulence Modeling for CFD. DCW Industries, Inc., California.

[11] F. R. Menter. 1994. Two-Equation Eddy-Viscosity Turbulence Models for Engineering Applications. AIAA Journal, 32(8):1598-1605.

[12] M. M. Gibson and B. E. Launder, 1978. Ground Effects on Pressure Fluctuations in the Atmospheric Boundary Layer. J. Fluid Mech., 86:491-511.

How to cite this article:

Habib M. Y. Djaaffar R. Numerical simulation and modeling of unsteady flow around an airfoil. (aerodynamic form). J. Fundam Appl Sci. 2014, 6(1), 116-126 